\title{
\#254 Waste Management Strategies for Sustainable Development
}

\section{Synonyms}

Waste management; strategy; sustainable development; higher education

\section{Definition}

Waste management refers to the activities and actions that handle waste materials. It includes collection, transportation, processing and disposal of waste. Waste prevention, recycling, reuse and recovery are important waste management strategies that eases the burden on landfills, conserves natural resources and saves energy. This helps utilize resources more effectively and sustainably.

\section{Introduction}

The world is besieged with growing pressure of waste management. The amount of waste has been increasing along with expanding population and rising human activities (The Washington Post, 2017; The World Bank, 2018). The World Bank estimated that there were approximately 1.3 billion tons of municipal solid waste generated globally in 2012, and the volume is expected to reach 2.2 billion tons by 2025 (Hoornweg \& Bhada-Tata, 2012). Waste levies a heavy tax on the environment and human health; it is also a barrier to socio-economic advancement. Waste is an unavoidable by-product of human development, but protecting the environment and safeguarding public health are equally important. To achieve viable economic, environmental, and social objectives, sustainable waste management strategies become highly desirable. Higher education institutions (HEIs) in this regard are crucial in achieving the objective of waste management for sustainable development, because the tertiary education sector is often considered as a key initiator of societal transition. Over the last two decades, an increasing number of HEIs have incorporated sustainable development (SD) into waste management practices. Since sustainable development is a relative new and abstract concept, the paradigm shift towards sustainability in waste management still presents a tremendous challenge to HEIs and contributes to the low rate of change of organizations (Lozano, Lozano, Mulder, Huisingh, \& Waas, 2013). To better promote implementation of sustainable development in HEIs, this chapter intends to provide information on the paradigm shift towards sustainability in waste management and the role of HEIs in facilitating the movement. The discussion would focus on waste management strategies for sustainable development in HEIs context. The chapter also highlights current challenges behind the movement. It is expected that this chapter would enlighten stakeholders of HEIs across the world about the development of waste strategies for sustainable development.

\section{Shifting the paradigm towards sustainability}

The sustainable development concept has become increasingly prominent since its appearance in the United Nations Conference on the Human Environment in 1972 in Stockholm. Defined in the Brundtland Report, the concept refers to "development that meets the needs of the present generation without compromising the ability of future generations to meet their own needs" (World Commission on Environment and Development, 1987). It is a holistic approach for human development which foregrounds a state of equilibrium between environmental protection, and economic and social progression for improving the 
quality of life; economic, social, and environmental needs for both the present and future generations could be balanced by incorporating the concept into concrete practices (cf. Leal Filho, 2011; Lozano, 2006).

Among the human activities, waste management is one of the areas that needs close attention in pursuit of sustainable development. Waste cause enormous negative impacts on economic development and human health. Every year in high-income countries, hundreds of million tons of municipal solid wastes are buried in landfills or incinerated (The Guardian, 2018; The New York Times, 2018); and most low-income countries dispose of waste in open dumps (Hoornweg \& Bhada-Tata, 2012; The Economist, 2018; The Times of India, 2018). Landfilling and incineration are the popular and common strategies for waste management; but none of them are sustainable practices because of the considerable environmental and financial costs (Nabavi-Pelesaraei, Bayat, Hosseinzadeh-Bandbafha, Afrasyabi, \& Chau, 2017; Zhang, Tan, \& Gersberg, 2010). For instance, both waste management facilities are often opposed by potential neighboring residents. Collecting and transporting waste for landfilling and incineration also produce greenhouse gas and cause great energy consumption. Landfills sites produce landfill gas and are expensive for maintenance; the problems associated with landfills would become a burden to future generations. Incineration cause air pollution if not well executed; it is also a massive inefficient use of materials if recyclable materials are not being separated before combustion. To meet the present needs and reserve the rights of development for future generations, a set of waste management strategies integrating the concept of sustainable development should be developed to achieve the goal of protecting the environment while yielding economic and social benefits. In this connection, HEIs have an important role in helping societies become more sustainable in waste management.

\section{The role of HEIs}

Historically, HEIs are major contributors of human development. The sector is expected "to play a pivotal role in sustainable development, economic growth, decent work, gender equality and responsible global citizenship in all regions" (UNESCO, 2015). It is an agent of social changes, which has a critical role in setting out principles of development, demonstrating relevant practices, and making improvements upon delivery. Specifically, universities may create sustainable future by increasing the awareness, knowledge, skills and values needed (Cortese, 2003). The institutions also serve as a role model of making the transition to sustainable lifestyles for now and for future generations (Cole, 2003, p. 30). Universities have a moral obligation to act and behave according to socio-environmental concerns (Armijo de Vega, Ojeda Benítez, \& Ramírez Barreto, 2008; Zhang, Williams, Kemp, \& Smith, 2011). Universities' substantial potential to catalyse and accelerate societal transitions towards sustainability (Stephens, Hernandez, Roman, Graham, \& Scholz, 2008) contributes to a growing demand from societies on HEIs regarding the actions of sustainability. HEIs are expected to drive the efforts towards sustainable development. Acting as a microcosm of society, daily activities and operations in colleges and universities generate considerable number of materials consumption. HEIs should address, involve and promote the minimization of negative effects of resources to help society make the transition to sustainable lifestyles (Velazquez, Munguia, Platt, \& Taddei, 2006, p. 812). Higher education can model waste management practices which shift towards sustainability for societies. Practical concerns and challenges for implementing sustainability in waste management would also set as reference to societies (Stephens et al., 2008). 


\section{Waste management strategies (WMS) in HEIs context}

4.1. Intervention techniques governing the development of WMS

Production of waste is closely associated with human behaviors such as consumption patterns and lifestyles; it is a mixed result of cultural, economic, and social environment where human behaviors are taken place (Hansen, Christopher, \& Verbuecheln, 2002). Steg and Vlek (2009) proposed two intervention techniques which aim at changing human behaviors and improving surrounding environments, namely, informational interventions and structural interventions (see Abrahamse \& Matthies, 2012 and Bolderdijk, Lehman, \& Geller, 2012 for a detailed review). The ultimate goal of WMS is minimization of waste. To meet the objective, the development of waste management strategies should be built on the challenges of changing individuals' attitudes and in turn their behaviors as well as individuals' surrounding environments where behaviors are taken place.

Informational interventions aim at changing individuals' attitudes, awareness, knowledge, perceptions, and norms which influence individuals' motivations for taking a behavior (Steg \& Vlek, 2009). There are different types of informational interventions. Providing information is the most commonly used intervention. Disseminating information about waste problems increases individuals' awareness and knowledge of the problem; it offers possible solutions of the problem for individuals to follow (Abrahamse \& Matthies, 2012). This can be done by launching education and promotional campaigns. Another strategy accompanying with information dissemination is prompting. It is usually a spoken or written message which reminds individuals to behave in an appropriate way, for example, a recycling slogan which draws individuals' attention to participate in recycling practices. Prompting information can also be presented in the form of picture, photos, or cartoon to increase its attractiveness. Our behaviors are partly influenced by people around us. It has always been the pressure of individuals to act upon according to perceptions and behaviors of their important others. The strategy of setting role model would strengthen social norms and inform individuals the perceptions and behaviors of others. Setting a goal and spelling out when, where, and how to reach the goal is goal-setting strategy. Usually, an attractive and easy-reached goal would increase individuals' incentive to engage in behaviors. Goal-setting strategy is closely related to two other informational interventions, namely, commitment and feedback. The former one is asking individuals to make a pledge to perform certain behaviors while the later one refers to disclosure of information about how well participated individuals perform the behaviors, for example, the volume of waste that an individual has been reduced over a given period of time.

Improvement of surrounding environments would facilitate behavioral changes. There are different external barriers to behavioral changes, for instance, lack of facilities to complement behavior taking. Structural strategies aim at removing these external barriers by reducing costs while increasing the attractiveness of participating in behaviors. Therefore, availability and quality of infrastructure and facilities, advancement of technology, and establishment of organizations and services which facilitate behavior engagement would be needed. Regulatory measures such as rules and policies would also change the circumstance and thus affect the decision of behavior taking. Moreover, every behavior is associated with consequences and people tend to obtain positive consequences and avoid negative consequences (Bolderdijk et al., 2012). Thus, rewards and penalties which based on the above assumption would be useful for creating incentives to individuals for behavioral changes. 


\subsection{WMS for sustainable development}

As mentioned above, daily activities of universities can contribute to pollution and environmental degradation; and common waste management strategies such as landfills and incineration are not sustainable practices. To shift the waste management paradigm to sustainability, developed strategies need to address socio-economic development without endangering public health and the environment. In this regard, waste management strategies should follow the priority order set out in the waste hierarchy in pursuit of sustainable development. Waste hierarchy was set by the European Commission for establishing preferred program priorities based on sustainability (Hansen et al., 2002, p. 3). It provides a framework for developing waste strategies for sustainable development. According to the hierarchy, a priority order for waste management strategies is prevention, reuse, recycling, and recovery; disposal would be the last resort for waste management. The following will present the strategies with reference to university context in more detail.

Waste prevention is highlighted as a top prioritized strategy for sustainable development. It is the first step that avoids a substance become waste. The strategy reduces the total amount of waste generated as well as the adverse impact associated with waste, and optimizes efficiency use of resources. The success of the strategy requires a change of both consumption and production patterns. Amutenya, Shackleton, and Whittington-Jones (2009) suggested that developing policies and regulations would transform waste prevention to a norm and campus-wide practice. Take paper products as an example. Double-spaced and single-sided hard copies of assignments and enormous printed documents for administration make paper products as the single largest component of waste stream in campus (Smyth, Fredeen, \& Booth, 2010). Setting up guidelines would facilitate reduction of generating paper waste, for example, providing guidelines to academic departments that students are no longer required to submit assignments printed in double-spaced and single-sided paper, or developing policies which require duplex printing for every administrative document, use electronic form to replace printed version of memo for circulation, or centralize all procurements for reduce printing paper (Zhang et al., 2011). Formulating policies also provide clear instructions for preventing the generation of waste. Particularly, green procurement policies with the objective of purchasing products and services that generate minimal waste and reduce adverse environmental impacts become more popular in universities around the world. Financial incentives can be applied to a variety of university activities. Canteen caterers may offer price reduction to participants who order less volume of meals. Students and staff who choose duplex and economic printing may receive cash rebate. To encourage more waste prevention behaviors, there must be provision of facilities to complement waste prevention practices, for instance, more hand driers should be provided to prevent the generation of paper towel waste. Waste prevention requires cooperation from different campus units. Therefore, in addition to various informational interventions for encouraging waste prevention, campaigns and promotional work that aim at raising awareness of and cooperation from different parties within the campus would be necessary.

Reuse is a key component of waste prevention; it is also the second prioritized strategy for achieving sustainable development according to the waste hierarchy. Reuse of products can extend products' life span and reduce the amount of waste directed to landfills or incineration. Procurement policy which includes the requirement of selecting long life-span products would be structurally important (Zhang et al., 2011). Besides, establishing exchange center in campus that offers support for reuse practices to students and staff (e.g. allocating products to new users) is suggested. It is expected that reuse of materials or products may 
not be accepted by every individual. In light of this, changing individuals' perceptions of reuse may be more important than improving the surrounding environments for facilitating behavior change. Other than popular promotional programs, setting up quality-assurance scheme which provides information about the quality of reused materials and products would be more effective for promoting reuse behavior.

Recycling is one of the most popular strategies adopted by universities for making campuses more sustainable. Recyclables provide economic value and further enhances the efficiency use of materials. The practice also reduces the volume of waste being dumped into landfill sites or incinerated, and thus causes less harmful effects on the environment. It involves processes that separate collected waste and convert recyclables into useable materials or new products. A large proportion of waste in HEIs is recoverable (Armijo de Vega et al., 2008). For example, there were 33\% and over 37\% recyclable materials in Brown University in USA and the Prince George campus of the University of Northern British Columbia in Canada, respectively (Brown University, 2017; Smyth et al., 2010); in some developing countries such as Philippine, about $90 \%$ solid waste are potential recoverable in faculty rooms in three universities in Baguio City (Anacio, 2017). Common examples of recyclables in university context are paper and paper products for administrative and academic purpose, disposable beverage containers, and food packaging materials.

Investment into recycling infrastructure and hardware contributes to a sound recycling strategy. Facilities such as recycling bins for various types of recyclables should be strategically positioned across campus. Location of distribution needs to be convenient enough that would reduce the cost of participating in recycling behavior (Kelly, Manson, Leiss, \& Ganesh, 2006). Novel and innovative structural interventions are highly encouraged for increasing the attractiveness of participating in recycling. For example, the Chinese University of Hong Kong has introduced PET recycling bins exclusively for bottles made from PET with a No. 1 code around the campus due to the costly source segregation for plastics ( 7 types of plastic wastes). The practice can sort out PET plastic bottles from other types of plastic bottles, reducing the cost and increasing efficiency of handling recycled plastic bottles (Chinese University of Hong Kong, 2015). Offering rewarding incentives such as redemption of gift or coupon to participants once they had recycled a certain amount of waste would also help boost recycling rate. Besides, developing regulations and policies advancing recycling practices in campus environment is utmost important for an effective recycling strategy. A potential structural intervention would be to institute policies requiring all university departments recycle common recoverable substances such as paper products, plastic bottles, glass bottles, and the arising waste electrical and electronic equipment (Zhang et al., 2011). All these structural recycling strategies would not be succeeded without adequate information provided. Interventions such as education campaigns (e.g. Kaplan, 2008), posters, eye-catching slogans, exhibitions, and games booth, prompts (e.g. Austin, Hatfield, Grindle, \& Bailey, 1993), goal setting (e.g. McCaul \& Kopp, 1982), and feedback (e.g. Kim, Oah, \& Dickinson, 2005) have been adopted by universities' recycling programs of previous studies (Kaplowitz, Yeboah, Thorp, \& Wilson, 2009). The information spreads messages such as the importance of recycling may change individuals' attitudes, beliefs, and level of responsibility for recycling (Schultz, 2002) and in turn encourage recycling behaviors. Quality of collected recyclables could also be improved by educating participants about the proper practices of recycling.

It is impossible that generated waste could be prevented, reused, or recycled. Recovering waste is an option after all previous strategies have been considered. Recovery refers to the processes of extracting energy or materials from the waste. For example, waste can turn into energy through thermal treatment; recovery of organic waste can be converted into energy and compost; materials recovered through recycling are of 
economic value. Although recovery is prioritized in a relatively low position in the waste hierarchy, the strategy contributes to sustainable development by reducing the demand of using resources as well as the amount of waste being buried in landfill sites. Food waste from campus canteens is a common substance used for recovery. For example, Ithaca College, USA, uses 5 tons of food waste per week to produce compost (Armijo de Vega et al., 2008). Since materials used for recovery (e.g. food waste) usually occupy a large space for storage and need effective odour control measures, facilities and space for storage and advance technologies for recovery (e.g. reducing energy consumption during recovery processes) are required. Besides, increasing awareness of students and staff by using various informational techniques would in turn gain support from them for waste recovery projects.

Disposal is perceived to be contradictory to sustainable development because it is inefficient in making use of potential resources, making energy consumption during waste collection and transportation, causing harmful effects to the environment and public health. However, not all waste can be prevented, reused, recycled, or recovered. With appropriate informational and structural inventions, disposal can also be a strategy that complies with the principle of sustainable development. Universities are suggested to make environmental-friendly disposal management compulsory; specifically, processes of collecting and transporting disposed waste should consume least energy and have minimal adverse environmental impact as possible. Setting goal such as to achieve zero waste to landfill by the targeted year would guide the implementation of other waste strategies (e.g. Arizona State University, 2012). Conducting disposal waste audit would give the university itself the performance of reducing waste for disposal (Appalachian State University, 2012).

\section{Looking forward: challenges of advancing sustainability in waste management}

In recent years, proliferated studies have been found that attachment to a place may cause behavioral responses on behalf of that place (Stedman, 2002). The attachment raises from different sources that related to a place, including place identity, emotional bond between individuals and a place, and connectedness to natural environment of a place (Giuliani, 2003; Scannell \& Gifford, 2010; Stedman, 2002). Empirical studies have proved that place attachment is a key driver of taking specific forms of behavior such as private-sphere pro-environmental behaviors (Devine-Wright \& Clayton, 2010). In other words, actions taken to protect the environment of a specific geographical location, such as recycling and waste reduction, can be considered as place-based behaviors. Such kind of attachment varies across cultures, geographical locations, and societies due the heterogeneity of society, culture, and individuals' backgrounds, which could in turn affect the place-based behaviors. The increased evidence of place-based behaviors (e.g. Scannell \& Gifford, 2010; Stedman, 2002; Uzzell, Pol, \& Badenas, 2002) signifies that waste strategies which are developed based on traditional intervention techniques may not be sufficient to drive the momentum of changing individuals' behaviors. Therefore, alongside informational and structural intervention techniques, human-place relations such as individuals' emotional bonds with a place have the potential to form an independent set of techniques to influence individuals' behaviors.

Another challenge of taking responsible waste management would be the effectiveness of strategies. Informational strategies such as education campaigns may receive a quick response from individuals, but the effectiveness may last for only a short period of time. It is less possibly to maintain the behavior shift and participation rate is likely to diminish once education campaigns were removed or prompts/commitments become insensitive to targeted individuals over a long period of time. By contrast, 
Iyer and Kashyap (2007) pointed out that effectiveness of structural strategies such as policy measures and regulations are relatively long lasting and return for a more satisfied result. It is because most structural strategies have already been institutionalized, which the behaviors had become normal and routinized. Majority of waste management strategies adopted by HEIs were developed based on the informational and structural techniques. Their effectiveness of changing behavior remains uncertain. It may be a challenging work when deciding the proportion of resources allocated to each type of strategy. Therefore, more empirical studies on effectiveness of WMS should be conducted in HEIs. It is expected that the empirical evidence would provide insights on which strategy would be the best working practice for a specific institution or what combination of strategies would optimize the effectiveness of behavior shift.

Many higher education institutions were found to be heavily relying on recycling programs as their waste management strategies for sustainable development (Fournier, 2008; Smyth et al., 2010). It is true that recycling diverts waste from landfills or incineration. However, processing recyclables requires the use of energy and resources (Smyth et al., 2010) which implies that recycling alone is not sufficient for achieving the goal of sustainable development (Armijo de Vega, Ojeda-Benítez, \& Ramírez-Barreto, 2003). A genuine implementation of sustainable development in campus operations should include multiple waste management strategies which greater emphasis is placed on waste prevention. More strategies targeting at reducing waste at source should be developed to articulate the commitment of sustainability goals. For example, starting from July 2017 the University of Hong Kong bans the sale and distribution of water in disposable plastic bottles in one liter or less in volume across its campus (University of Hong Kong, 2017). The institutionalized strategy provides clear instructions in moving campus operations beyond recycling. Overall, the shift towards sustainability in waste management requires complementation of diversified management strategies which follow the priority order set by the waste hierarchy (Tammemagi, 1999).

\section{Conclusions}

Rapid economic development results in more waste and thus poses greater threats to ecosystems and human health. Sustainable waste management is important that enables a steady socio-economic development and protects the environment and our health. It paves the way of development that fulfills the present needs without endangers future generations' development. HEIs would be increasingly important for leading the role of societal transition in this regard. This chapter summarized the role of HEIs in facilitating the paradigm shift towards sustainability and provided a set of waste management strategies for sustainable development with reference to HEIs context. Specifically, informational and structural intervention techniques should be incorporated into the development of waste management strategies. Next, different types of strategies for sustainable development according to the overarching principles set by the waste hierarchy were discussed. Prevention should be prioritized above reuse, recycling, recovery, and disposal. There are potential challenges of the sustainable WM movement. This chapter would assist universities to set out waste management strategies for sustainable development, which in turn, serve the role model of building a better and resilient society.

\section{Cross-References}

Sustainability on campus

Sustainability perceptions

Sustainability policy initiatives 


\section{References}

Abrahamse, W., \& Matthies, E. (2012). Informational strategies to promote pro-environmental behaviour: Changing knowledge, awareness and attitudes. In L. Steg, A. E. van den Berg, \& J. I. M. de Groot (Eds.), Environmental psychology: an introduction (pp. 223-232). Hoboken, United States: John Wiley and Sons Ltd.

Amutenya, N., Shackleton, C. M., \& Whittington-Jones, K. (2009). Paper recycling patterns and potential interventions in the education sector: A case study of paper streams at Rhodes University, South Africa. Resources, Conservation and Recycling, 53(5), 237-242.

Anacio, D. B. (2017). Designing Sustainable Consumption and Production Systems in Higher Education Institutions: The Case of Solid Waste Management. In W. Leal Filho, M. Mifsud, C. Shiel, \& R. Pretorius (Eds.), Handbook of Theory and Practice of Sustainable Development in Higher Education: Volume 3 (pp. 3-25). Cham: Springer International Publishing.

Appalachian State University. (2012). Waste Reduction Strategic Plan Working Toward a Zero Waste Campus. North Carolina, United States.

Arizona State University. (2012). Waste Management, ASU aim to eliminate solid waste [Press release]. Retrieved from https://asunow.asu.edu/content/waste-management-asu-aim-eliminate-solid-waste

Armijo de Vega, C., Ojeda-Benítez, S., \& Ramírez-Barreto, M. E. (2003). Mexican educational institutions and waste management programmes: a University case study. Resources, Conservation and Recycling, 39(3), 283-296.

Armijo de Vega, C., Ojeda Benítez, S., \& Ramírez Barreto, M. E. (2008). Solid waste characterization and recycling potential for a university campus. Waste Management, 28(Supplement 1), S21-S26.

Austin, J., Hatfield, D. B., Grindle, A. C., \& Bailey, J. S. (1993). Increasing recycling in office environments: the effects of specific, informative cues. Journal of Applied Behavior Analysis, 26(2), 247-253.

Bolderdijk, J. W., Lehman, P. K., \& Geller, E. S. (2012). Encouraging pro-environmental behaviour with rewards and penalties. In L. Steg, A. E. van den Berg, \& J. I. M. de Groot (Eds.), Environmental psychology: an introduction (pp. 233-242). Hoboken, United States: John Wiley and Sons Ltd.

Brown University. (2017). Tenth Annual Sustainability Progress Report.

Chinese University of Hong Kong. (2015). CUHK introduces innovative ideas to promote waste reduction and recycling [Press release]. Retrieved from https://www.cpr.cuhk.edu.hk/en/press detail.php?id=2103

Cole, L. (2003). Assessing sustainability on Canadian University campuses: development of a campus sustainability assessment framework. Canada: Royal Roads University.

Cortese, A. D. (2003). The Critical Role of Higher Education in Creating a Sustainable Future. Planning for Higher Education, 31(3), 15-22.

Devine-Wright, P., \& Clayton, S. (2010). Introduction to the special issue: Place, identity and environmental behaviour. Journal of Enviornmental Psychology, 30(3), 267-270.

Fournier, R. (2008). Recycling this! A look at campus recycling programs. In W. Simpson (Ed.), The green campus: meeting the challenge of environmental sustainability (pp. 191-200). Alexandria, VA: APPA.

Giuliani, M. V. (2003). Theory of attachment and place attachment. In M. Bonnes (Ed.), Psychological theories for enviornmental issues. Aldershot: Ashgate.

Hansen, W., Christopher, M., \& Verbuecheln, M. (2002). EU Waste Policy and Challenges for Regional and Local Authorities. Berlin, Germany: Ecological Institute for International and European Environmental Policy.

Hoornweg, D., \& Bhada-Tata, P. (2012). What a Waste: A Global Review of Solid Waste Management Urban Development Series Knowledge Papers. Washington, DC.: World Bank.

Iyer, E., \& Kashyap, R. (2007). Consumer recycling: role of incentives, information and social class. Journal of Consumer Behaviour, 6(32-47). 
Kaplan, K. (2008). In pursuit of recycling excellence at the University of Oregon. In W. Simpson (Ed.), The green campus: meeting the challenge of environmental sustainability (pp. 201-206). Alexandria, VA: APPA.

Kaplowitz, M. D., Yeboah, F. K., Thorp, L., \& Wilson, A. M. (2009). Garnering input for recycling communication strategies at a Big Ten University. Resources, Conservation and Recycling, 53, 612-623.

Kelly, T. C., Manson, I. G., Leiss, M. W., \& Ganesh, S. (2006). University community responses to oncampus resource recycling. Resources, Conservation and Recycling, 47(1), 42-55.

Kim, S., Oah, S., \& Dickinson, A. M. (2005). The Impact of Public Feedback on Three RecyclingRelated Behaviors in South Korea. Environment and Behavior, 37, 258-274.

Leal Filho, W. (2011). About the Role of Universities and Their Contribution to Sustainable Development. Higher Education Policy, 24, 427-438.

Lozano, R. (2006). Incorporation and institutionalization of SD into universities: breaking through barriers to change. Journal of Cleaner Production, 14, 787-796.

Lozano, R., Lozano, F. J., Mulder, K., Huisingh, D., \& Waas, T. (2013). Advancing Higher Education for Sustainable Development: international insights and critical reflections. Journal of Cleaner Production, 48, 3-9.

McCaul, K. D., \& Kopp, J. T. (1982). Effects of goal setting and commitment on increasing metal recycling. Journal of Applied Psychology, 67(3), 377-379.

Nabavi-Pelesaraei, A., Bayat, R., Hosseinzadeh-Bandbafha, H., Afrasyabi, H., \& Chau, K.-w. (2017). Modeling of energy consumption and environmental life cycle assessment for incineration and landfill systems of municipal solid waste management-A case study in Tehran Metropolis of Iran. Journal of Cleaner Production, 148, 427-440.

Scannell, L., \& Gifford, R. (2010). The relations between natural and civic place attachment and proenviornmental behavior. Journal of Enviornmental Psychology, 30(3), 289-297.

Schultz, P. W. (2002). Knowledge, information, and household recycling: examining the knowledgedeficit model of behavior change. In T. Dietz (Ed.), New tools for environmental protection. Washington, DC: National Academy Press.

Smyth, D. P., Fredeen, A. L., \& Booth, A. L. (2010). Reducing solid waste in higher education: The first step towards 'greening' a university campus. Resources, Conservation and Recycling, 54, 10071016.

Stedman, R. (2002). Toward a social psychology of place: Predicting behaviour from place-based cognitions, attitude, and identity. Environment and Behavior, 34, 561-581.

Steg, L., \& Vlek, C. (2009). Encouraging pro-environmental behaviour: An integrative review and research agenda. Journal of Enviornmental Psychology, 29, 309-317.

Stephens, J. C., Hernandez, M. E., Roman, M., Graham, A. C., \& Scholz, R. W. (2008). Higher education as a change agent for sustainability in different cultures and contexts. International Journal of Sustainability in Higher Education, 9(3), 317-338.

Tammemagi, H. (1999). The waste crisis: landfills, incinerators and the search for a sustainable future. New York, NY, USA: Oxford University Press.

The Economist. (2018). The poor world and the rich world face different problems with their waste. The Economist.

The Guardian. (2018). UK's plastic waste is a burning issue. The Guardian. Retrieved from https://www.theguardian.com/environment/2018/oct/22/uks-plastic-waste-is-a-burning-issue

The New York Times. (2018). Your Recycling Gets Recycled, Right? Maybe, or Maybe Not. The New York Times.

The Times of India. (2018). Delhi: Industries promise to clean up act The Times of India.

The Washington Post. (2017). The world is drowning in ever-growing mounds of garbage. The Washington Post.

The World Bank. (2018). Solid Waste Management. The World Bank. 
UNESCO. (2015). Draft Preliminary Report Concerning the Preparation of a Global Convention on the Recognition of Higher Education Qualifications.

University of Hong Kong. (2017). Policy on disposable plastic bottles. Retrieved January, 5, 2018, from http://www.sustainability.hku.hk/sustainable-hku/ditch-disposable/PolicyDPB

Uzzell, D., Pol, E., \& Badenas, D. (2002). Place identification, social cohesion, and environmental sustainability. Environment and Behavior, 34, 26-53.

Velazquez, L., Munguia, N., Platt, A., \& Taddei, J. (2006). Sustainable university: what can be the matter? Journal of Cleaner Production, 14(9-11), 810-819.

World Commission on Environment and Development. (1987). Our Common Future. Oxford, United Kingdom: Oxford University Press.

Zhang, D. Q., Tan, S. K., \& Gersberg, R. M. (2010). Municipal solid waste management in China: status, problems and challenges. Journal of Environmental Management, 91(8), 1623-1633.

Zhang, N., Williams, I. D., Kemp, S., \& Smith, N. F. (2011). Greening academia: Developing sustainable waste management at Higher Education Institutions. Waste Management, 31, 1606-1616. 